\title{
EDUKASI KESEHATAN OSTEOPOROSIS DAN PEMERIKSAAN KEPADATAN TULANG DI POSBINDU SOKA INDAH RW 05 KELURAHAN BENCONGAN
}

\author{
DOI: https://doi.org/10.33024/jkpm.v4i5.4195
Yenni Ferawati Sitanggang ${ }^{1^{*}}$, Riama Marlyn Sihombing ${ }^{2}$, Marini Purwani $^{3}$
1,2,3Fakultas Keperawatan, Universitas Pelita Harapan \\ Disubmit: 12 April $2021 \quad$ Diterima: 08 Mei $2021 \quad$ Diterbitkan: 30 September 2021 \\ Email: yenni.sitanggang@uph.edu
}

\begin{abstract}
ABSTRAK
Osteoporosis adalah keadaan dimana menurunnya kepadatan tulang yang menyebabkan pasien mengalami kejadian fraktur. Osteoporosis seringkali dikaitkan dengan kejadian yang umum terjadi pada lanjut usia, akan tetapi menurut osteoporosis dapat juga mengenai usia muda. Wanita dikatakan memiliki faktor resiko paling tinggi terjadinya osteoporosis dibandingkan pria. Hal ini bisa disebabkan karena wanita memiliki ukuran tubuh yang lebih kecil dari pria, kurangnya paparan matahari dan kurangnya konsumsi makanan yang mengandung kalsium. Di posbindu Soka Indah RW 05 Bencongan Indah memiliki 40 lansia dengan usia antara 46 sampai dengan $>60$ tahun. Data yang didapatkan dari kader posbindu ada satu lansia wanita yang sudah terdiagnosa osteoporosis, dan dua lansia usia antara 50-60 tahun yang mengeluh kakinya sakit. Edukasi tentang osteoporosis belum pernah dilakukan di posbindu bencongan RW 05. Sebagai upaya untuk meningkatkan pengetahuan lansia tentang osteoporosis maka edukasi Kesehatan serta pemeriksaan kepadatan tulang pada seluruh lansia di Posbindu Bencongan RW 05 dilakukan. Hasil yang didapatkan dari kegiatan ini adalah terjadinya peningkatan pemahaman lansia terkait osteoporosis dengan rata-rata nilai 10 poin meningkat dari pre-test. Selanjutnya hasil kepadatan tulang didapatkan hasil sebanyak tiga lansia memiliki kepadatan tulang yang normal, 11 orang mengalami osteopenia dan 14 orang lainnya terskrining osteoporosis.
\end{abstract}

Kata kunci: Edukasi, Kepadatan tulang, Osteoporosis

\begin{abstract}
Osteoporosis is a condition where bone density is decreased which can caused fracture. Osteoporosis often associated with an incident which generally occur in elderly people, but based on health ministry, osteoporosis can also occur to young people. Women is told have a high risk of osteoporosis compared to men. This is because wome have a small body size than men, minimum of sun exposure, insufficient intake of foods that contain calcium. In Posbindu Soka Indah Bencongan has 40 elderly people with 46 - above 60 years old range. Data taken from cadres, there was one of them who was diagnosed of osteoporosis and two of the elders in
\end{abstract}


their 50-60 years old were complaining of sore legs. Health education about osteoporosis has never been given in the posbindu bencongan. Therefore, as an effort in order to increase elderly's knowledge in osteoporosis, health education and also bone density assessment in posbindu were done. The result showed there was an increased point in the post=test result of 10 points which means elderly's knowledge was increase. Furthermore, the bone density result was three people had a normal bone density, while 11 people had low bone density and 14 people were screened to have osteoporosis.

Keyword: Bone density, Education, osteoporosis

\section{PENDAHULUAN}

Osteoporosis merupakan penyakit kronis yang sangat umum dan terjadi dibanyak negara diseluruh dunia. Osteoporosis seringkali tidak terdiagnosa tau bahkan tidak diobati khususnya pada lanjut usia, padahal penanganan osteoporosis dapat dicegah. Osteoporosis adalah kondisi dimana tulang menjadi sangat lemah dan rapuh (World Health Organization (WHO), 2004). Menurut Kemenkes (2015), osteoporosis didefinisikan sebagai penyakit tulang yang ditandai dengan menurunnya massa tulang/kepadatan tulang dan disertai dengan rusaknya arsitektur tulang yang akan mengakibatkan penurunan kekuatan tulang yang bisa juga disebut sebagai pengeroposan tulang. Pengeroposan tulang pada umumnya dikaitkan dengan penyakit yang biasa menyerang lanjut usia atau orang yang sudah lebih tua dan menjadi salah satu faktor penyebab osteoporosis dan osteopenia (Alswat, 2017). Konsekuensi paling serius dari gangguan ini adalah patah tulang/fraktur. Fraktur merupakan komplikasi dari gejala sisa osteoporosis (Curtis and Safford, 2012; Sozen, Ozisik and Calik Basaran, 2017).

Osteoporosis disebutkan juga sebagai "silent disease" sampai pada akhirnya seorang pasien itu mengalami fraktur . Akan tetapi, ada beberapa hal yang bisa dilakukan untuk mencegah terjadinya patah tulang yaitu; pengobatan osteoporosis, mencegah jatuh, menggunakan proteksi panggul/hip protector (Armis, 2005). Osteoporosis pada umumnya seringkali dianggap sebagai penyakit wanita. Akan tetapi I dari 8 pria yang berusia lebih dari 50 tahun juga punya kecenderungan mengalami osteoporosis dan mengakibatkan fraktur di berbagai area tubuh seperti lengan bawah, tulang belakang dan pinggul (D'Amelio and Isaia, 2015). Gauthier et al., (2011) dalam studi nya menyebutkan bahwa sebanyak 11.494 juta wanita berusia $>50$ tahun mengalami osteoporosis dengan $50 \%$ diantaranya direntang usia dibawah 65 tahun.

Posbindu Soka Indah RW 05 termasuk dalam wilayah layanan Puskesmas Kutai. Psobindu ini merupakan posbindu yang aktif melayani perawatan kepada lanjut usia. Posbindu Soka Indah memiliki sebanyak 40 lansia aktif dengan kategori lansia muda sampai lansia yang berusia antara 46 sampai dengan $>60$ tahun. Posbindu ini dipimpin oleh tiga kader yang aktif melakukan kegiatan-kegiatan posbindu setiap minggunya seperti pemeriksaan tekanan darah menggunakan alat tensimeter otomatis, menimbang berat badan, dan melaksanakan olah raga khusus untuk lansia. Menurut salah satu kader puskesmas, dua lansia wanita berusia 59 tahun dan 62 tahun beberapa kali mengeluh kaki nya sering merasa kram, merasa lebih lemah dan tidak kuat lama untuk beraktivitas. Dua lansia tersebut tidak pernah mengunjungi 
dokter untuk menanyakan keluhannya selama ini. Selanjutnya, satu lansia di posbindu tersebut ada yang telah mengalami menopause dini di usia 47 tahun. Sebuah studi menyebutkan bahwa usia tua bisa dikaitkan dengan kejadian osteoporosis (Armis, 2005). Mayoritas lansia di posbindu ini adalah perempuan, dimana hal ini dapat menjadi satu faktor pendukung terjadinya osteoporosis pada wanita dua kali lebih tinggi dibanding laki-laki (Fatmah ,2008).

Menurut penanggung jawab kader posbindu Soka Indah, belum ada satu pun dari lansia yang tercatat di posbindu Soka Indah yang pernah memeriksakan kepadatan tulang. Selanjutnya, edukasi tentang osteoporosis pun belum pernah dilakukan sebelumnya di posbindu Soka Indah. Berdasarkan latar belakang diatas, tim pelaksana merasa sangat penting untuk tim melakukan edukasi kesehatan tentang osteoporosis serta melakukan pemeriksaan kepadatan tulang pada lansia di posbindu Soka Indah yang bertujuan untuk meningkatkan pengetahuan lansia juga kader posbindu tentang osteoporosis sekaligus mendapatkan hasil pemeriksaan tentang kepadatan tulang para lansia yang dapat dijadikan data dasar untuk pemeriksaan lanjutan.

\section{MASALAH}

Osteoporosis dapat terjadi pada wanita maupun pria direntang usia yang juga beragam. Edukasi tentang osteoporosis di posbindu Soka Indah belum pernah diadakan, selanjut nya baik lansia maupun kader posbindu belum memahami tentang osteoporosis. Sehingga hal ini menjadi penting mengingat mayoritas lansia adalah wanita yang menjadi faktor resiko tertinggi terjadinya osteoporosis dan mengingat rentang usia lansia di posbindu Soka Indah juga beresiko untuk terjadi nya osteoporosis. Oleh karena itu, pemberian edukasi melalui ceramah terkait osteoporosis akan memberikan manfaat meningkatkan pengetahuan lansia maupun kader posbindu. Selain itu, pemeriksaan kepadatan tulang juga akan dilakukan sehingga lansia mendapatkan data penunjang untuk melakukan pemeriksaan lanjutan.

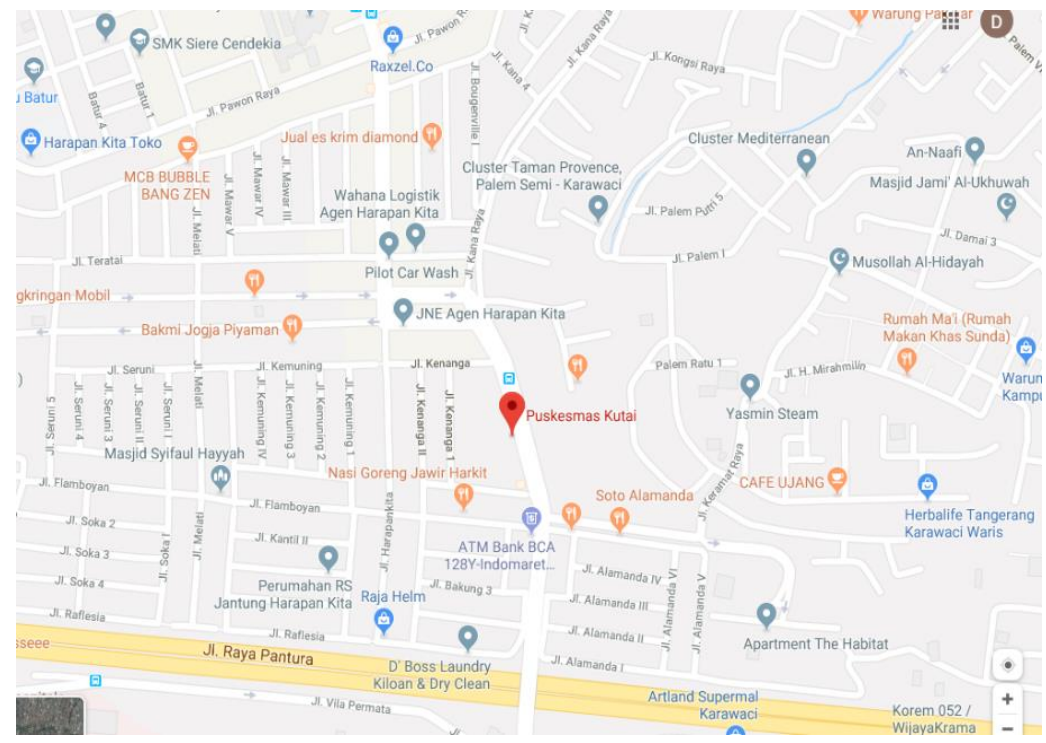

Gambar 2.1 Peta Lokasi Kegiatan Pengabdian Kepada Masyarakat 


\section{METODE}

Kegiatan pengabdian pada masyarakat ini dilaksanakan dengan memberikan penjelasan melalui edukasi Kesehatan tentang osteoporosis melalui media power point dan leaflet. Sasaran dalam edukasi ini meliputi seluruh lansia yang terdaftar di posbindu Soka indah sebanyak 40 lansia. Pada saat penjelasan materi, setiap anggota tim serta kader mendampingi lansia guna menghindari kesalahpahaman atau miskomunikasi tentang edukasi yang berlangsung. Edukasi Kesehatan diberikan sekitar 30 menit yang selebihnya dilanjutkan dengan tanya jawab dari peserta kepada pembicara. Edukasi Kesehatan meliputi pemaparan tentang pengertian osteoporosis, gejala osteoporosis, hal yang dilakukan untuk mencegah terjadi osteoporosis dan penanganan osteoporosis.

Untuk mengukur tingkat pengetahuan peserta, tim pelaksana memberikan pre-test yang dikerjakan oleh peserta. Diakhir pemaparan materi, selanjutnya peserta mengisi post-test untuk melihat apakah terjadi peningkatan pengetahuan dan pemahaman peserta tentang topik osteoporosis yang diberikan. Setelah keseluruhan materi selesai, tim beserta petugas laboratorium dari RS. Fauzan melakukan pemeriksaan kepadatan tulang masing-masing lansia di posbindu Soka Indah. Total sebanyak 37 lansia datang saat penyampaian materi berlangsung, akan tetapi hanya 28 lansia yang mengikuti pre dan post-test sekaligus dilakukan pemeriksaan kepadatan tulang. Sebagai bentuk evaluasi pengetahuan peserta, tim memeriksa hasil pre-test dan post-test serta melakukan perbandingan nilai antara pre dan post-test. Selanjutnya, setelah pemeriksaan kepadatan tulang dilakukan, tim memberikan penjelasan tentang hasil skrining kepadatan tulang kepada peserta dan meminta peserta menyimpan hasil skrining guna sebagai acuan jika membutuhkan konsultasi Kesehatan selanjutnya.

Evaluasi kegiatan edukasi ini dilakukan diakhir kegiatan dengan memberikan beberapa pertanyaan kepada lansia dan kader. Form evaluasi berisi tentang penilaian peserta pada saat pembicara menyampaikan materi, menilai apakah penyuluhan bermanfaat dan menilai jalannya kegiatan serta lingkungan selama edukasi berlangsung.

\section{HASIL DAN PEMBAHASAN}

HASIL

Hasil kegiatan ini akan digambarkan dalam beberapa hasil yaitu karakteristik peserta antara lain jenis kelamin dan usia, hasil skrining kepadatan tulang dan hasil pre-test, post-test serta hasil rata-rata pre dan post-test.

Tabel 4.1. Distribusi frekuensi karakteristik peserta $(n=37)$

\begin{tabular}{|l|c|c|}
\hline \multicolumn{1}{|c|}{ Variabel } & Jumlah & Persentase (\%) \\
\hline Jenis kelamin & & \\
\hline Laki-Laki & 8 & 21.62 \\
\hline Perempuan & 29 & 78.38 \\
\hline Usia & & \\
\hline $40-50$ tahun & 9 & 24.32 \\
\hline $51-60$ tahun & 21 & 56.76 \\
\hline$>60$ Tahun & 7 & 18.92 \\
\hline
\end{tabular}


Tabel 4.1 menunjukkan dari total 37 peserta lansia yang hadir, mayoritas adalah perempuan sebanyak 29 orang lansia $(78.38)$ dengan mayoritas berusia diantara rentang 51-60 tahun.

Tabel 4.2. Hasil skrining kepadatan tulang $(n=28)$

\begin{tabular}{|l|c|c|}
\hline \multicolumn{1}{|c|}{ Variabel } & Jumlah & Persentase (\%) \\
\hline Kepadatan Tulang & & \\
\hline Normal & 3 & 10.71 \\
\hline Osteopenia & 14 & 50 \\
\hline Osteoporosis & 11 & 39.29 \\
\hline
\end{tabular}

Tabel 4.2 menunjukkan bahwa setengah dari lansia (50\%) di posbindu Soka Indah mengalami osteopenia (massa tulang rendah). Selanjutnya sebanyak 11 lansia (39.29\%) memiliki hasil skrining osteoporosis. Walaupun demikian tiga lansia diantaranya memiliki kepadatang tulang normal (10.71\%).

Tabel 4.3. Hasil rata-rata pre dan post-test $(n=28)$

\begin{tabular}{|c|c|c|}
\hline Variabel & Rata-rata nilai pretest & $\begin{array}{c}\text { Rata-rata nilai } \\
\text { postest }\end{array}$ \\
\hline Edukasi & 39.56 & 49.5 \\
\hline
\end{tabular}

Dari tabel 4.3 dapat disimpulkan bahwa terjadi peningkatan pengetahuan lansia sebelum dan setelah diedukasi. Terlihat dari rerata pre-test (sebelum penyuluhan) 39,56 dan post-test (setelah penyuluhan) 49.5.

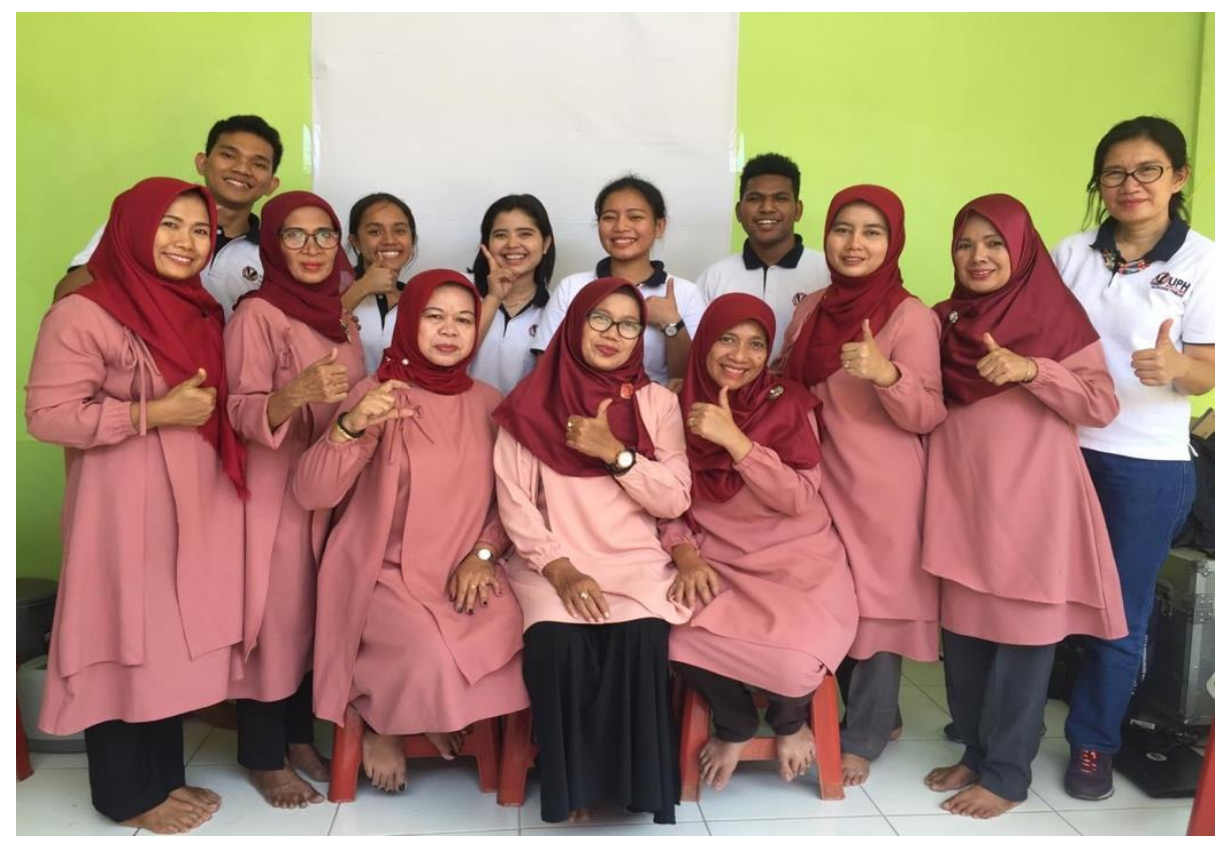

Gambar 2.2 Foto Tim PKM Bersama Kader Posbindu Soka Indah 


\section{PEMBAHASAN}

Pada hasil PkM ini ditemukan kejadian osteoporosis terjadi pada 11 orang responden $(39.29 \%)$ dan sedangkan osteopenia pada 14 orang $(50 \%)$ dari seluruh responden berjumlah 28 lansia. Hanya tiga lansia yang memiliki kepadatan tulang normal. Diketahui dari data oleh kader bahwa rata-rata lansia tidak bekerja dan berada hanya dirumah, dimana aktivitasnya hanya terbatas. Para lansia juga diketahui tidak berolahraga secara rutin dan lansia pria mayoritas adalah perokok. KEMENKES RI, (n.d.) menegaskan pencegahan untuk tidak terjadinya osteoporosis adalah antara lain berolahraga, diet yang tepat, mengkonsumsi kalsium, menghindari konsumsi alkohol dan konsumsi rokok secara berlebihan. Hal ini juga diperkuat oleh The royal Australian college of general practitioners (2019) bahwa mengkonsumsi kalsium khususnya pada lansia sangat direkomendasikan mengingat lansia beresiko tinggi terjadi osteoporosis karena kekurangan /defisiensi vitamin D.

Olahraga yang didukung dengan asupan kalsium dan vitamin D yang cukup dapat membantu menambah kepadatan tulang dimana terjadi keseimbangan antara osteoclast dan osteoblast (Prasetya, Wirjatmadi and Adriani, 2015). Selanjutnya, tidak hanya kalsium dan vitamin $D$, indeks masa tubuh juga memengaruhi kepadatan tulang. Sebagaimana disebutkan dalam studi yang dilakukan oleh Mardiyah \& Sartika (2014), bahwa IMT (Indeks Massa Tubuh) memiliki hubungan yang signifikan terhadap kepadatan tulang. Selanjutnya dijelaskan bahwa individu yang memiliki IMT <23.49 $\mathrm{kg} / \mathrm{m} 2$ mengalami gangguan kepadatan tulang 5.5 kali lebih tinggi dibandingkan dengan Individu yang memiliki IMT dengan rentang 23.49-27.36 yang hanya memiliki resiko 2.2 kali. Akan tetapi pada saat kegiatan, tim pelaksana tidak mengkaji IMT lansia sehingga tidak dapat mengkaitkan hubungan keduanya.

Selanjutnya ditegaskan dalam studi yang dilakukan oleh Mardiyah \& Sartika (2014) bahwa usia lansia diatas 50 tahun memiliki peluang sebesar 2.6 kali mengalami gangguan kepadatan tulang dibandingkan lansia yang berusia dibawah 50 tahun. Hal ini sesuai dengan data yang didapatkan bahwa mayoritas lansia di posbindu Soka Indah berada di rentang usia 50-60 tahun. Tercatat kejadian osteoporosis pada kegiatan ini adalah sebanyak 11 lansia (39.29\%). Hal ini didukung oleh Khadilkar \& Mandlik (2015) bahwa wanita mengalami penurunan estrogen yang menyebabkan terjadinya osteoporosis lebih tinggi pada wanita. Tidak hanya usia yang menajdi factor pencetus terjadinya osteoporosis, D’Amelio and Isaia, (2015) menyebutkan bahwa kejadian stroke, konsumsi alkohol berlebihandan rokok secara berlebihan juga penggunaan kortikosteroid dalam waktu yang lama dapat menyebabkan resiko osteoporosis. Walaupun demikian, dalam kegiatan pengabdian ini tidak dilakukan analisa hubungan antara usia dengan angka kejadian osteoporosis maupun osteopenia pada lansia. Sehingga kegiatan berikut nya dimasa yang akan datang perlu untuk dapat mengkaji lebih luas lagi hubungan factor pencetus dengan kejadian osteoporosis pada lansia.

Perubahan gaya hidup sehat dengan rutin beraktivitas, konsumsi kalsium atau makan makanan yang banyak mengandung kalsium, membiasakan diri terpapar dengan sinar matahari agar tidak terjadi kekurangan vitamin $D$, berhenti dari rokok dan alcohol merupakan saran yang dapat diberikan pada lansia agar terhindar dari kemungkinan kejadian osteoporosis (Statham and Aspray, 2021). Kekurangan kalsium dan vitamin $\mathrm{D}$ pada orang tua akan mengakibatkan peningkatan resiko jatuh dan terjadi nya fraktur (Curtis and Safford, 2012). Meskipun vitamin D tidka mungkin mencegah kejadian patah tulang, akan tetapi pengobatan vitamin $D$ dan kalsium 
dapat mengurangi kejadian patah tulang pada lansia yang lemah (Avenell et al., 2009).

Pengetahuan merupakan salah satu faktor yang dapat memengaruhi perilaku seseorang. Perilaku juga berhubungan dengan status kesehatan orang. Sehingga diharapkan dari peningkatan pemahaman lansia tentang osteoporosis dapat merubah perilaku serta status Kesehatan lansia.

\section{KESIMPULAN}

Kegiatan pengabdian kepada masyarakat di Posbindu Bencongan mampu meningkatkan pengetahuan partisipan tentang osteoporosis. Kegiatan ini sesuai dengan tujuan awal kegiatan dimana terjadi peningkatan pengetahuan dan terdapat hasil pemeriksaan kepadatan tulang pada lansia di posbindu soka indah. Sehingga diharapkan kegiatan ini dapat menjadi dasar untuk para lansia mencegah terjadinya osteoporosis dan meningkatkan Kesehatan.

\section{UCAPAN TERIMA KASIH}

Penulis mengucapkan terima kasih sebesar-besarnya kepada Kader Posbindu Bencongan serta Universitas Pelita Harapan yang telah mendukung tim dalam pelaksanaan kegiatan pengabdian kepada masyarakat ini dengan Nomor PkM: PM102-M/FoN/X/2019.

\section{DAFTAR PUSTAKA}

Alswat, K. A. (2017) 'Gender Disparities in Osteoporosis', Journal of Clinical Medicine Research. doi: 10.14740/jocmr2970w.

Armis. (2005). Osteoporosis pada Lansia. Available at: https://ugm.ac.id/id/newsPdf/931-osteoporosis-pada-lansia.

Avenell, A. et al. (2009). 'Vitamin D and vitamin D analogues for preventing fractures associated with involutional and post-menopausal osteoporosis', Cochrane Database of Systematic Reviews. doi: 10.1002/14651858.CD000227.pub3.

Curtis, J. R. and Safford, M. M. (2012) 'Management of osteoporosis among the elderly with other chronic medical conditions', Drugs and Aging. doi: 10.2165/11599620-000000000-00000.

D'Amelio, P. and Isaia, G. C. (2015). 'Male osteoporosis in the elderly', International Journal of Endocrinology. doi: 10.1155/2015/907689.

Fatmah, F. (2008). 'OSTEOPOROSIS DAN FAKTOR RISIKONYA PADA LANSIA ETNIS JAWA', Media Medika Indonesiana.

Gauthier, A. et al. (2011) 'Epidemiological burden of postmenopausal osteoporosis in the UK from 2010 to 2021: Estimations from a disease model', Archives of Osteoporosis. doi: 10.1007/s11657-011-0063-y.

Kemenkes. (2015). 'Data \& Kondisi Penyakit Osteoporosis di Indonesia', Pusat Data \& Informasi Kementrian Kesehatan RI.

KEMENKES RI. (no date) osteoporosis. Available at: http://p2ptm.kemkes.go.id/uploads/VHcrbkVobjRzUDN3UCs4eUJ0dVBndz0 9/2017/10/Infografis_Osteoporosis.pdf (Accessed: 9 February 2021). 
Khadilkar, A. V. and Mandlik, R. M. (2015) 'Epidemiology and treatment of osteoporosis in women: An Indian perspective', International Journal of Women's Health. doi: 10.2147/IJWH.S54623.

Mardiyah, S. and Sartika, R. A. D. (2014) 'Gangguan Kepadatan Tulang pada Orang Dewasa di Daerah Urban dan Rural', Kesmas: National Public Health Journal. doi: 10.21109/kesmas.v0i0.380.

Prasetya, D., Wirjatmadi, B. and Adriani, M. (2015) 'Pengaruh Pemberian Susu yang Difortifikasi (Kalsium dan VitaminD) dan Senam Osteoporosis Terhadap Kepadatan Tulang pada Wanita Pra Lansia di Wilayah Kerja Puskesmas Banyuanyar Kabupaten Sampang.', Ilmiah Kedokteran, pp. 25-37.

Sozen, T., Ozisik, L. and Calik Basaran, N. (2017) 'An overview and management of osteoporosis', European Journal of Rheumatology. doi: 10.5152/eurjrheum.2016.048.

Statham, L. and Aspray, T. J. (2021) 'Osteoporosis in older adults', Medicine (United Kingdom). doi: 10.1016/j.mpmed.2020.10.003.

World Health Organization (WHO). (2004). 'WHO SCIENTIFIC GROUP ON THE ASSESSMENT OF OSTEOPOROSIS AT PRIMARY HEALTH Care Level', World Health Organization. doi: 10.1016/S0140-6736(02)08761-5. 